\title{
Analysis of Silting Characteristics of Rivers in Shanghai Old Town Based on Dredging Data Statistics (1617-1915)
}

\author{
Liu Qingqing ${ }^{1,2, a^{*}}$
}

\begin{abstract}
${ }^{1}$ Department of Design, Shanghai Academy of Fine Arts, Shanghai University, BaoShan, Shanghai, China
${ }^{2}$ Department of Arts, School of Humanities and Social Sciences, Xi'an Jiaotong University, Beilin, Xi'an, Shaanxi, China

a*17357086@qq.com
\end{abstract}

\begin{abstract}
Based on the quantitative research method to count the number and frequency of dredging in different periods and spatial distribution in Shanghai Old Town from 1617 to 1915, this paper reveals the different characteristics of the siltation of rivers in Shanghai Old Town before and after the opening. Statistics show that the frequency of dredging was low before the opening of Shanghai, but increased sharply after the opening and Shanghai local autonomy period. This shows that the degree of river siltation was becoming more and more serious. After the opening, the structural siltation of the river network was further intensified, leading to the decline of the old dredging efficiency.
\end{abstract}

Keywords: Shanghai Old Town, Dredge, Structural Siltation, Statistical Analysis

\section{基于疏浚数据统计的上海老城厢河浜淤塞特征分析 (1617-1915)}

\author{
刘清清 1,2, a
}

\footnotetext{
${ }^{1}$ 上海大学上海美术学院设计系, 宝山区, 上海, 中国

2 西安交通大学人文学院艺术系, 碑林区, 西安, 陕西, 中国

a17357086@qq.com
}

\section{摘要}

本文采用定量研究方法统计了 1617-1915 年上海老城厢不同时期和空间分布的河浜疏浚次数与频次, 揭示了 上海老城厢河浜淤塞在开埠前后的差异性特征。统计显示开埠前疏浚频次较低, 开埠后、自治后两期频次急剧 增多。这说明了河浜淤塞程度逐期愈发严重。而开埠后河浜网络的结构性淤塞进一步加剧，导致旧时疏浚功效 日益式微。

关键词: 上海老城厢, 疏浚, 结构性淤塞, 统计分析

\section{1. 前言}

自嘉靖三十二年(公元 1553 年)上海筑城以来，河 道淤塞因此而更加严重。如目前所见最早的上海旧县志 - — 《万上海县志》就记载老城厢一带的方浜、薛家 浜、侯家浜等主干河浜因筑城而 “断塞”，局部浜段或存 “一衣带” 或 “几于平壤”。[1]此后, 旧县志的水道治 绩中一直都有记载淤塞情况。目前学界大多引用局部浜
段淤塞史料，采用定性描述的方法将淤塞原因归结于河 浜水环境的日益脆弱和恶化。[2]但是对其淤塞程度和 特征并未有深入分析。正是因为疏浚一直是传统时代上 海地方政府针对河道淤塞的通行办法, 所以历次疏浚活 动数据即是判断河浜淤塞程度的重要信息。本文将采用 定量方法统计分析疏浚次数与频次, 以此进一步揭示上 海老城厢一带河浜淤塞在开埠前后的差异性特征。 


\section{2. 数据整理与统计}

老城厢河浜疏浚情况在明清和民国时期上海地方 志中均有大量记载。《申报》建报以来也有不少浚河报道, 也可作为县志中较近时间记录的印证和补充资料。这是 本文统计信息的重要来源。本文整理所得有效统计样本 48 条。样本历时 298 年, 最早记录是万历四十五年 (1617 年）知县吕浚开浚县城内外水道, 最晚记录是民国四年 （1915 年）工巡捐局挑浚西门外肇嘉浜、陆家浜。

根据 48 次疏浚年份, 计算相邻两次的间隔年数。这 是统计的基础数据。为了更加精确判断，本文引入 “疏 浚频次 (年/次)” 计算, 即前次疏浚的间隔年数总和除 以次数总和。1915 年度疏浚频次即是统计期内总频次。 淤塞和疏浚关系判断依据的是间隔年数、疏浚频次与淤 塞程度之间的关系。间隔年数越短表明疏浚频次越高, 淤塞程度越严重, 淤塞速度亦较快。反之, 淤塞程度较 轻, 淤塞速度较慢。统计期分为开埠前 (1617-1836)、 开埠后 (1855-1893) 和自治后 (1895-1915) 三个时期, 并求得分期频次。统计数据如表 1 , 并得到面积和折线 组合图如图 1 所示。

本文还将统计不同区域河浜的淤塞情况。本文研究 的空间范围定位在老城厢一带即以城濠为界分为城外 与城内河浜、城濠三大区域, 而暂不包括租界区域内的 河浜以及离城较远的其他浜段。城外河浜包括小东门外 方浜、大东门外肇嘉浜、老西门外迤西至斜桥段肇嘉浜、 小南门外薛家浜、城南之陆家浜 5 条, 城内包括小东门 内方浜、侯家浜、黑桥浜、大东门至老西门段的肇嘉浜、 小南门内乔家浜至薛家桥迤南转西至城根的薛家浜 5 条, 加之城濠总计是 11 条河浜段。按三个分期统计不同分 区疏浚次数和频次如表 2、图 2 所示, 以及汇总各河浜 （含城濠）疏浚年份如图 3 所示。

\section{3. 总体疏浚频次和淤塞程度}

图 1 中波峰表示前后两次疏浚间隔年数长，波谷则 表示间距年数短。间隔年数长意味着长时间没有疏浚, 这说明河浜淤塞情况尚可; 间距年数短意味着短时间内 疏浚活动多, 这说明河浜淤塞程度高、速度快。

以统计期内总频次 (6.2 年/次) 为界, 图 1 显示 1855 年之前波动较其后要大得多。1855 年以前分别在 1652、1720、1775、1836 年达到 4 次较大波峰, 在 1693 、 $1746 、 1755 、 1803$ 年出现 4 次较大波谷, 波峰、波谷分 别相差 41、26、20、33 年。这说明在这 238 年里总体上 每 20-40 年才会频繁疏浚。反言之, 疏浚后河浜尚能维 持数十年的较长时间畅通。而 1855 年后的情况大为不 同, 间隔年份均没有超过总频次, 并且波动幅度都在低 数区域。不但波峰、波谷数增加即均有 8 次, 而且间距 年数以 1-2 年居多。这比起前期几十年的间距可谓相差 太多。这说明在 1855 年至 1915 年的 60 年里疏浚活动 特别频繁, 即疏浚后畅通维持时间特别短。简言之, 1855 年后河浜淤塞程度非常严重和速度更快。

再来分析逐年频次特征。图中显示 1855 年是统计 期内最后一个波峰。以此为界，前期仅在 1672 年 (13.8 年/次) 和 1740 年 (15.4 年/次) 出现 2 次稍大波峰,
此后至 1855 年间略有波动, 但此年后频次折线一直呈 现下行趋势。在 1797 年至 1811 年的 14 年里频繁疏浚 使得 1811 年后河道本可以保持贯通，但是在 1855 年被 打破而呈现逐年频次增加之势。这表明 1855 年后淤塞 程度越发严重和频繁，以致疏浚间隔年数越来越短。频 次被打破的原因在于 1853-1855 年小刀会起义期间攻占 县城。清军和法军、起义军的军事活动对包括河浜在内 的县城造成了巨大破坏。1855 年克复县城后, 巡道赵德 辙檄海防同知吴煦、知县孙丰因此开浚内外城河支港。 [3]

值得注意 1859 年后又以 1893 年波峰为界, 前之 34 年里有 3 段平峰即 1872-1876、1881-1883、1887-1889 年，大致间隔 2-4 年; 而之后的 22 年里并没有平峰，差 值大都在 1-3 年。不同于 1855 年因战争外力影响, 1859 年后的低位频次波动更多的与人口增长带来的人地关 系紧张有关。在城墙围合而用地有限的旧上海县城中, 人口增加带来的直接影响就是侵占河浜, 以及产生更多 地生活垃圾倾倒河中。这就越发造成了河道的淤塞和不 畅。这一点可以从旧上海人口增长情况得到印证。已有 研究表明, 上海老城厢人口由开埠前的 20 余万人增长 到 1854 年前后的约 54.4 万人， 1910 年后 67.2 万人， 再到 1914 年 117.3 万人。[4] 可见, 淤塞程度实质上反 映的是人地关系。

总之, 从间隔年数与频次折线来看, 1855 年、1895 年是上海建城以来浚河活动的两个重要节点。这两个时 间点刚好与上海开埠和地方自治一致。结合上海近代历 史，我们不妨把整个疏浚活动划分为开埠前、开埠后、 自治后三个时期来考察。

开埠前从 1617 年至 1836 年的 219 年里有 20 次浚 河记录, 其疏浚平均频次约在 11 年/次, 即是每 11 年才 有一次疏浚; 开埠后 1855 年至 1893 年的 38 年有 17 次 记录, 其疏浚平均频次急增为 3.4 年/次，即是每 3.4 年 就有一次疏浚。这说明较之前期开埠后河浜疏浚频次大 为增加, 也表明了淤塞程度更加严重; 而自治后 1895 年 至 1915 年的 20 年里有 11 次记录，其疏浚平均频次更 是 2 年/次，即间隔 2 年就有一次疏浚。频次再次增加表 明此期河浜淤塞在 3 期之中最为严重。因此, 综合这 298 年里 48 条记录来看，上海开埠后 1855 年、1893 年是疏 浚频次变化的重要分水岭, 也反映了河浜淤塞程度逐期 更加严峻。

表 1 历次河浜疏浚的间隔年数和频次

\begin{tabular}{|c|c|c|c|}
\hline \multicolumn{4}{|c|}{ 开埠前 } \\
\hline 年份 & $\begin{array}{c}\text { 间隔年数 } \\
\text { (年) }\end{array}$ & $\begin{array}{c}\text { 频次 } \\
\text { (年/次) }\end{array}$ & $\begin{array}{c}\text { 分期频次 } \\
\text { (年/次) }\end{array}$ \\
\hline 1617 & 0 & 0.0 & \\
\cline { 1 - 2 } 1621 & 4 & 2.0 & \\
\hline 1652 & 31 & 11.7 & \multirow{2}{*}{11.0} \\
\hline 1672 & 20 & 13.8 & \\
\hline 1684 & 12 & 13.4 & \\
\hline 1693 & 9 & 12.7 & \\
\hline 1720 & 27 & 14.7 & \\
\hline
\end{tabular}




\begin{tabular}{|c|c|c|c|}
\hline 1740 & 20 & 15.4 & \\
\hline 1745 & 5 & 14.2 & \\
\hline 1746 & 1 & 12.9 & \\
\hline 1750 & 4 & 12.1 & \\
\hline 1753 & 3 & 11.3 & \\
\hline 1755 & 2 & 10.6 & \\
\hline 1775 & 20 & 11.3 & \\
\hline 1783 & 8 & 11.1 & \\
\hline 1797 & 14 & 11.3 & \\
\hline 1801 & 4 & 10.8 & \\
\hline 1803 & 2 & 10.3 & \\
\hline 1811 & 8 & 10.2 & \\
\hline 1836 & 25 & 11.0 & \\
\hline \multicolumn{4}{|c|}{ 开埠后 } \\
\hline 年份 & $\begin{array}{c}\text { 间隔年数 } \\
\text { (年) }\end{array}$ & $\begin{array}{c}\text { 频次 } \\
\text { (年/次) }\end{array}$ & $\begin{array}{l}\text { 分期频次 } \\
\text { (年/次) }\end{array}$ \\
\hline 1855 & 19 & 11.3 & \multirow{8}{*}{3.4} \\
\hline 1858 & 3 & 11.0 & \\
\hline 1859 & 1 & 10.5 & \\
\hline 1864 & 5 & 10.3 & \\
\hline 1870 & 6 & 10.1 & \\
\hline 1872 & 2 & 9.8 & \\
\hline 1874 & 2 & 9.5 & \\
\hline 1876 & 2 & 9.3 & \\
\hline
\end{tabular}

\begin{tabular}{|c|c|c|c|}
\hline 1880 & 4 & 9.1 & \\
\hline 1881 & 1 & 8.8 & \\
\hline 1882 & 1 & 8.5 & \\
\hline 1883 & 1 & 8.3 & \\
\hline 1886 & 3 & 8.2 & \\
\hline 1887 & 1 & 7.9 & \\
\hline 1888 & 1 & 7. 7 & \\
\hline 1889 & 1 & 7.6 & \\
\hline 1893 & 4 & 7.5 & \\
\hline \multicolumn{4}{|c|}{ 自治后 } \\
\hline 年份 & $\begin{array}{c}\text { 间隔年数 } \\
\text { (年) }\end{array}$ & $\begin{array}{c}\text { 频次 } \\
\text { (年/次) }\end{array}$ & $\begin{array}{l}\text { 分期频次 } \\
\text { (年/次) }\end{array}$ \\
\hline 1895 & 2 & 7.3 & \multirow{11}{*}{2.0} \\
\hline 1896 & 1 & 7.2 & \\
\hline 1899 & 3 & 7. 1 & \\
\hline 1901 & 2 & 6.9 & \\
\hline 1902 & 1 & 6.8 & \\
\hline 1904 & 2 & 6.7 & \\
\hline 1905 & 1 & 6.5 & \\
\hline 1907 & 2 & 6.4 & \\
\hline 1909 & 2 & 6.3 & \\
\hline 1910 & 1 & 6.2 & \\
\hline 1915 & 5 & 6.2 & \\
\hline
\end{tabular}

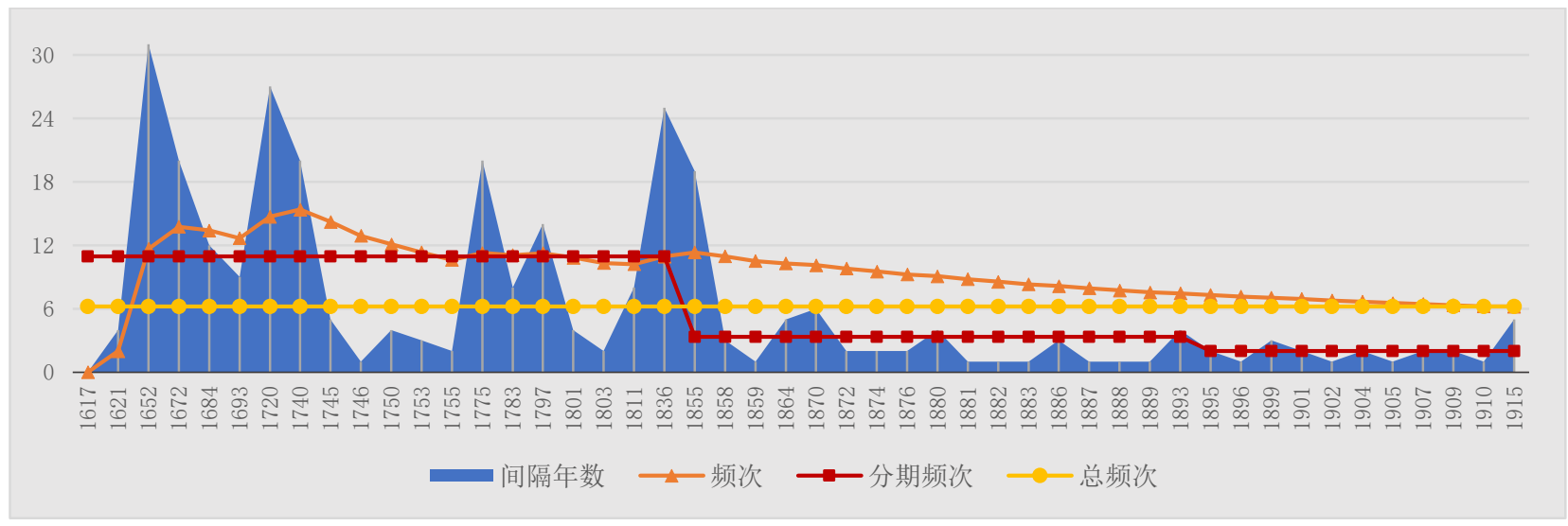

图 1 历次疏浚的间隔年数、频次分布图

\section{4. 分区疏浚频次和淤塞河浜}

前文是从长时段尺度来考察疏浚和淤塞情况。从 间隔年数、频次和分期频次三线综合考察和互证，将 疏浚分为开埠前、开埠后和自治后 3 个时期是恰当的。 现在不妨再从空间分布的角度仔细考察城外与城内 河浜、城濠三大区域的河浜疏浚情况。(表 2、图 2)
首先，三个分区的疏浚次数均逐期减少。其中从 同期疏浚次数占比来看，除城外河浜占比保持在 $37 \%$ 外，城濠占比保持在 14\%-19\%区间，城内河浜保持在 43\%-48\%区间。总体上看, 传统时代疏浚区域以城内为 主, 城外次之, 城濠则最少。这是因为作为人口聚居 区域, 城内河浜利用和侵占情况较多, 秽物、垃圾更 易倾倒河浜，所以其淤塞情况更为严重。而城外河浜 一般作舟船运输之用、沿浜居民较少, 城濠开浚工程 量大等原因导致后两者疏浚力度并不如城内河浜。 
其次, 三个分区的疏浚频次却是逐期增加, 特别 是开埠后更为明显。开埠前三分区的频次最高在每 14 年疏浚一次, 其中城内、外两区频次基本在 15 年/次 左右, 而城濠频次则在每 31 年一次。开埠后的两个 时期中, 城内河浜疏浚频次大为增加并保持 3 年/次, 城外河浜疏浚频次也在 3-4 年/次, 城濠疏浚频次增
加到 7-10 年/次。三个分区在开埠后的疏浚频次均较 开埠前提高了 3-4 倍多。而且, 总体频次从前期平均 每 6 年一次增加为后两期的每 1 年就有一次疏浚。这 表明在空间区域上城厢一带河浜淤塞总体情况逐期 愈发严峻。这与前节表征是一致的。

表 2 三个时期的分区疏浚次数与频次

\begin{tabular}{|c|c|c|c|c|c|c|c|c|c|c|c|c|}
\hline \multirow[b]{2}{*}{ 分区 } & \multicolumn{4}{|c|}{ 开埠前（1617-1836） } & \multicolumn{4}{|c|}{ 开埠后（1855-1893） } & \multicolumn{4}{|c|}{ 自治后（1895-1915） } \\
\hline & 次数 & $\begin{array}{l}\text { 同期 } \\
\text { 占比 }\end{array}$ & 年距 & 频次 & 次数 & $\begin{array}{l}\text { 同期 } \\
\text { 占比 }\end{array}$ & 年距 & 频次 & 次数 & $\begin{array}{l}\text { 同期 } \\
\text { 占比 }\end{array}$ & 年距 & 频次 \\
\hline 城濠 & 7 & $18.92 \%$ & \multirow{3}{*}{219} & 31 & 4 & $14.81 \%$ & \multirow{3}{*}{38} & 10 & 3 & $18.75 \%$ & \multirow{3}{*}{20} & 7 \\
\hline 城内河浜 & 16 & $43.24 \%$ & & 14 & 13 & $48.15 \%$ & & 3 & 7 & $43.75 \%$ & & 3 \\
\hline 城外河浜 & 14 & $37.84 \%$ & & 16 & 10 & $37.04 \%$ & & 4 & 6 & $37.50 \%$ & & 3 \\
\hline 合计 & 37 & $100.00 \%$ & & 6 & 27 & $100.00 \%$ & & 1 & 16 & $100.00 \%$ & & 1 \\
\hline
\end{tabular}

注: 频次 $=$ 年距/次数。

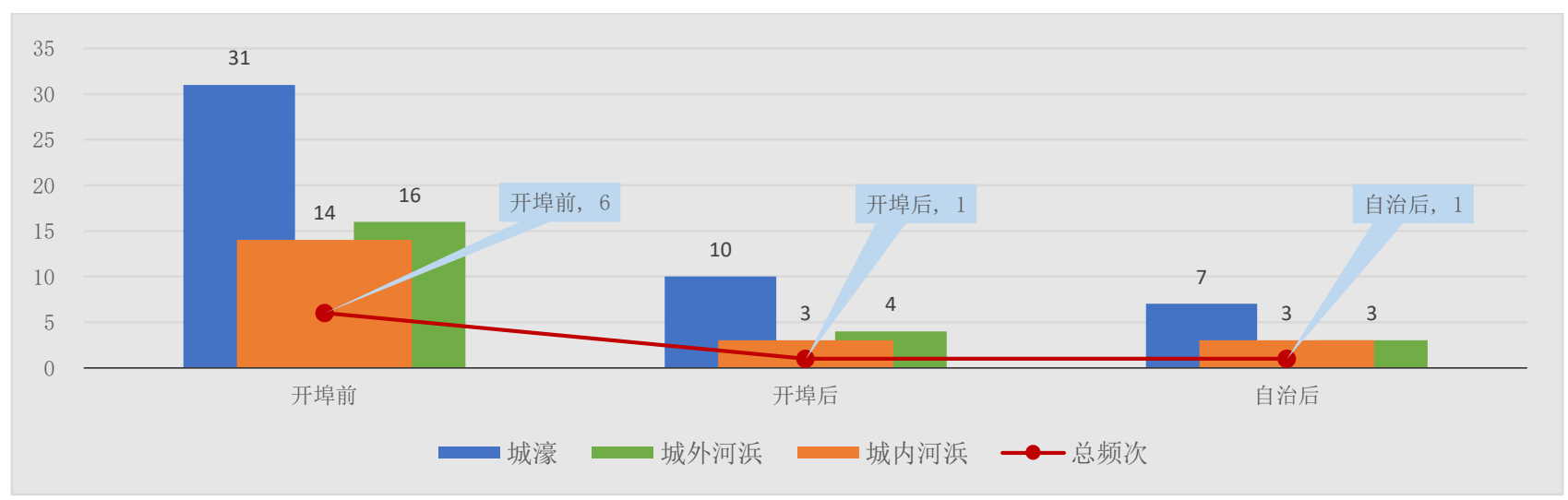

图 2 三个时期的分区疏浚频次

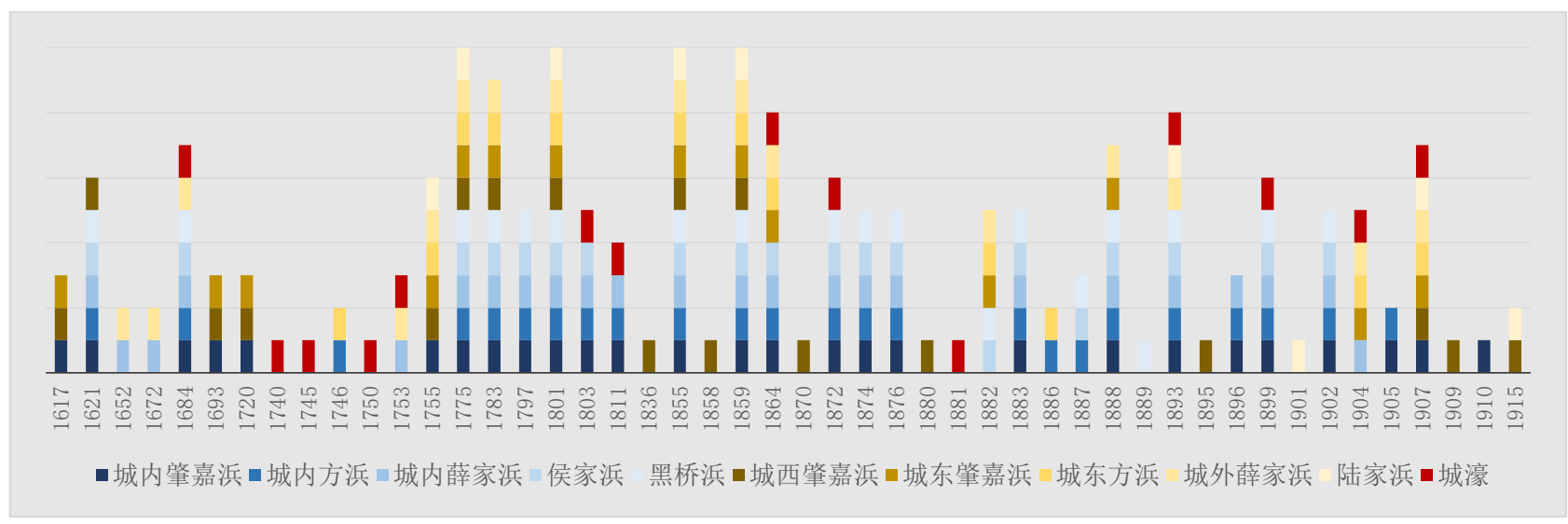

图 3 城濠、城内外河浜疏浚年度汇总

再次, 我们重点再考察一下三区河浜同时疏浚的 情况。这将有助于我们探讨河浜网络的整体淤塞情况。 在图 3 中, 蓝色系表示的是城内河浜, 黄色系则是城 外河浜, 红色为城濠。这其中有两点需要注意:
一是，城内外 10 条河浜同步大浚的年度。大浚 意味着需要通过疏浚全部河浜才能保证河网整体贯 通, 这从侧面表明河浜网络的淤塞特征。开埠前的 219 年中城内河浜全浚 6 次, 分别是 1621、1684、1775、 
1783、1797、1801 年。其中城外河浜一同大浚有 1775 、 1801 年 2 次, 前后相差 26 年。这一城内外同浚的情 况在开埠后则大为不同。开埠后城内河浜全浚的年份 有 1855、1859、1872、1874、1876、1883、1888、1893 年。此 38 年间 8 次疏浚依次相距 4、13、2、2、7、 $5 、 5$ 年。其中 $1855 、 1859$ 年 2 次中城外河浜是一同 大浚, 前后相差仅 4 年。而在自治后仅有 $1899 、 1902$ 年 2 次城内全浚, 相隔只有 3 年。不过此期以 1903 年为界, 前期开浚侧重城内河浜, 后期注重的是城外 河浜。尽管城内外大浚的情况并未出现, 不过 19011910 年间每隔 1-2 年的总体开浚频次表明自治后局 部浜段小浚更为频繁。由此, 城内外河浜同步大浚的 年度分布与间隔间数情况表明: 开埠前城内外河浜的 结构性淤塞已经出现, 并以城内河浜局域网络最为严 重; 再到开埠后结构性淤塞加剧, 大浚已经难以保持 持久畅通, 以致自治后的 20 世纪初只能采取常年小 浚试图来延续河浜 “生命”。正如 1907 年总工程局筹 划浚河时所言, 唯有 “统年捞挖, 周而复始, 不致间 断, 或可免大浚之劳。” [5] 但效果却还是常浚常淤、 浚毕即淤。

二是, 作为城内外河浜网络的连贯水道一一城濠 与城内外河浜同步疏浚情况。其在开埠前后均有 7 次 疏浚。在开埠前, 仅有 $1684 、 1753$ 年 2 次是与少数 城内外河浜一并疏浚的, 其余有 2 次仅是与城内河浜 同步, 有 3 次是单独开浚的。可以说, 城濠与城内外 河浜同时疏浚情况并不常有。而在开埠后的两期中, 城濠与城外河浜同步疏浚的年份有 1864、1893、1904、 1907 年 4 次, 其余有 2 次（1872、1899 年）与城内 外河浜同步。尽管有 1 次单独开浚, 但次年城内外河 浜相继疏浚（1881、1882 年)。这可认定开埠后城濠 基本与城外河浜开浚是同步的且次数较多。综合来看, 城濠同步疏浚频次增加再次证明了包括城濠在内的 河浜网络结构性淤塞在开埠后更为严重。结构性淤塞 的最终结果即是河浜功能的整体㿈疾, 而无论是同步 大浚还是常年小浚的治理办法并不能有效阻止这一 趋势而显得日益失效。

\section{5. 结论}

综上所述, 通过对 48 条疏浚记录的次数、频次 的数量统计和分析, 表明开埠后的 1855 年是老城厢 河浜淤塞程度的重要分水岭。就开埠前、开埠后和自 治后的三期来看, 前期疏浚频次较低, 后两期频次急 剧增多。疏浚频次逐期增加说明河浜淤塞程度愈发严 重。特别是开埠后河浜网络的结构性淤塞更为加剧, 导致依靠全数河浜同步大浚和局部常年小浚的方式 也都难以维持浜道长久畅通。这才在租界卫生观念和 “填浜筑路” 先例的启示下, 华界开始考虑 “由浚改 填”。1907 年黑桥浜的填筑开启了老城厢“填浜筑路” 的序幕。因此, 河浜结构性淤塞严重进而导致疏浚旧 法失效是后来 “填浜筑路”得以实施的现实空间原因。

\section{REFERENCES}

[1] H. F. Yan. (1588) Local gazetteer of Shanghai in Wangli of Ming Dynasty. Shanghai.

[2] Wu Junfan. (2010) Re-construction and Analysis on the Creek Degeneration of Shanghai Region from 1900 to 1949. Journal of Chinese Historical Geography., 25: 26-39.

[3] B. S. Ying. (1782) Local gazetteer of Shanghai in Tongzhi of Qing Dynasty. Shanghai.

[4] Y. N. Zhou.(1980) A study of population changes in old Shanghai. Shanghai People's Publishing House, Shanghai.

[5] X. Wu. (1918) Local gazetteer of Shanghai in Republic Of China. Shanghai. 